Volume 11

Issue 3 Global Approaches to Atrocity

Prevention: Theory, Practice, and the State of

Article 5 the Field

3-2018

\title{
National Mechanisms for the Prevention of Atrocity Crimes
}

Samantha Capicotto

The Auschwitz Institute for Peace and Reconciliation

Rob Scharf

The Auschwitz Institute for Peace and Reconciliation

Follow this and additional works at: https://digitalcommons.usf.edu/gsp

\section{Recommended Citation}

Capicotto, Samantha and Scharf, Rob (2018) "National Mechanisms for the Prevention of Atrocity Crimes," Genocide Studies and Prevention: An International Journal: Vol. 11: Iss. 3: 6-19.

DOI:

http://doi.org/10.5038/1911-9933.11.3.1502

Available at: https://digitalcommons.usf.edu/gsp/vol11/iss3/5

This is brought to you for free and open access by the Open Access Journals at Digital Commons @ University of South Florida. It has been accepted for inclusion in Genocide Studies and Prevention: An International Journal by an authorized editor of Digital Commons @ University of South Florida. For more information, please contact digitalcommons@usf.edu. 
National Mechanisms for the Prevention of Atrocity Crimes

\author{
Samantha Capicotto \\ The Auschwitz Institute for Peace and Reconciliation \\ New York, NY, USA \\ Rob Scharf \\ The Auschwitz Institute for Peace and Reconciliation \\ New York, NY, USA
}

\title{
What is a National Mechanism?
}

National Mechanisms for the Prevention of Genocide and other Atrocity Crimes are officially established bodies that include representatives from multiple areas of government relevant to the prevention of atrocity crimes. ${ }^{1}$ " Atrocity crimes" refers to three legally defined crimes under international law: war crimes, crimes against humanity, and genocide. ${ }^{2}$ National Mechanisms have been established to lead the development of a coordinated national strategy for the prevention of such crimes on behalf of their government.

The inclusion of representatives from all relevant areas of the state enables National Mechanisms to carry out an initial system-wide assessment of strengths and weaknesses from the perspective of atrocity prevention. Following this assessment, the National Mechanism supports the development and implementation of the necessary preventive policies to bolster the state's resilience to atrocity crimes. National Mechanisms are not intended to be the sole body of government tasked with thinking about prevention. Instead, they are meant to be the primary body responsible for ensuring that the entirety of the state is thinking about, and working towards, prevention.

National Mechanisms are vehicles through which states are able to exercise their responsibility to prevent genocide under their obligations as parties to the United Nations Convention for the Prevention and Punishment of the Crime of Genocide, as well as their responsibilities to prevent atrocity crimes as parties to other relevant international treaties, regional protocols, and as a product of their own national legislation. There is no single prescribed method for establishing a National Mechanism. However, a growing number of governments have looked to pre-existing institutions to incorporate this agenda, while others have chosen to establish new structures with the sole mandate of atrocity crimes prevention.

With regard to the structure of these bodies, ministries of foreign affairs, justice, defense and where they exist, national human rights institutions - are regularly represented. Additionally, in some countries, ministries of education and national security forces are represented. In Latin America, national and international civil society organizations often play an advisory and support role through the provision of technical assistance, capacity building, and output monitoring. In the Great Lakes Region of Africa, by contrast, a heightened level of civil society engagement with National Mechanisms has been observed. In this region, representatives of civil society have membership in the Mechanisms alongside their government colleagues. National Mechanisms differ from state to state, but four major themes emerge in their mandates and activities:

1. Risk assessment and early warning, including data gathering and analysis using an atrocity prevention lens, in order to detect patterns of group vulnerability and to alert the appropriate authorities so that they are able to take the recommended course of early action;

\footnotetext{
${ }^{1}$ The information presented in this article is drawn primarily from an annual publication produced by the Auschwitz Institute for Peace and Reconciliation (AIPR), an international non-governmental organization that works with states to prevent genocide and other atrocity crimes. Specifics relating to the parameters and activities of the National Mechanisms are reported by the members of the bodies themselves and aggregated by AIPR to provide a practical resource for use by practitioners in the field.

${ }^{2}$ David Scheffer, "Genocide and Atrocity Crimes," Genocide Studies and Prevention: An International Journal 1, no. 3 (2006).
} 
2. Development of training programs for civil servants and other relevant actors in society, which offer preventive approaches and practical tools that are able to be employed at the local and national levels;

3. Recommendation and elaboration of policies geared towards the protection of vulnerable populations from risks of genocide and other atrocity crimes; and

4. Communication and partnership building with regional and international organizations on issues related to the prevention of genocide and other atrocity crimes. ${ }^{3}$

Across the globe, the majority of active National Mechanisms are at an early stage of development, capacity building, and work plan implementation. However, each year the Mechanisms engage more profoundly in targeted preventive programming and policy development, resulting in the whole-of-government approach to atrocity crimes prevention gaining both momentum and legitimacy. The following sections detail the work of specific National Mechanisms in the Great Lakes Region of Africa and Latin America on atrocity crimes prevention.

\section{The Kenyan National Committee for the Prevention and Punishment of the Crime of Genocide, War Crimes, Crimes Against Humanity and All Forms of Discrimination History} On March 22, 2012, Kenya's Permanent Secretary of the Ministry of Foreign Affairs, Mr. Thuita Mwangi, officially launched the Kenyan National Committee (KNC). The Committee was established and complies with the International Conference on the Great Lakes Region (ICGLR) Protocol for the Prevention and Punishment of Genocide, War Crimes, Crimes Against Humanity and All Forms of Discrimination, which all founding ICGLR Member States ratified on November 29, 2006. This Protocol reaffirms the responsibility of Member States to domesticate and operationalize their duties under international law to combat atrocity crimes. One of the measures under the document calls for the establishment of a Regional Committee for the Prevention and Punishment of the Crime of Genocide, War Crimes, Crimes Against Humanity and all forms of Discrimination. The ICGLR Regional Committee subsequently required all ICGLR Member States to establish their own National Committees to operationalize these duties under both the regional Protocol and international law.

The launch of the Kenyan National Committee was followed by two days of training on Early Warning Systems (EWS), facilitated by the UN Office of the Special Advisers on the Prevention of Genocide and the Responsibility to Protect (UN OSAPG).

Mandate

The Committee has a mandate to:

- Regularly review situations at both the national and county levels for the purpose of preventing genocide, war crimes, crimes against humanity, and all forms of discrimination;

- Collect and analyze information related to genocide, war crimes, crimes against humanity, and discrimination;

- Alert both national and county governments in a timely manner to take urgent measures to prevent potential atrocity crimes;

- Suggest specific measures to effectively fight impunity for these crimes;

- Contribute to raising awareness and education on peace and reconciliation through national and county-level programs;

- Recommend policies and measures to guarantee the rights of victims of the crimes of genocide, war crimes, and/or crimes against humanity to truth, justice and compensation, as well as their rehabilitation, while taking into account gender-specific issues and ensuring that gender-sensitive measures are implemented; and

\footnotetext{
${ }^{3}$ The Auschwitz Institute for Peace and Reconciliation (AIPR), National Mechanisms for the Prevention of Genocide and other Atrocity Crimes: Effective and Sustainable Prevention Begins at Home (New York: 2015), 3, accessed December 28, 2017, http://www.auschwitzinstitute.org/wp-content/uploads/2015/06/AIPR National Mech Booklet 2015.pdf.
} 
- Monitor the National Program on Disarmament, Demobilization, Rehabilitation, Repatriation and Reinstallation (DDRRR) for former child soldiers, ex-combatants and combatants.

\section{Structure}

The National Committee operates under the guidance of a National Chairperson, who works in consultation with the Regional Committee, the National Coordinator of the Great Lakes Region, and other arms of the Kenyan government. The membership of the National Committee is drawn from governmental departments and non-governmental/civil society organizations. The Committee's membership is currently comprised of representatives from: the Ministry of Provincial Administration and Internal Security, the Ministry of Justice, National Cohesion and Constitutional Affairs, the State Law Office, the Director of Public Prosecutions, the Kenya Police, the Office of National Cohesion and Integration Commission, the Kenya National Commission on Human Rights, Truth, Justice and Reconciliation, the Law Society of Kenya, the International Commission of Jurists, FIDA Kenya, Peace Net Kenya, the Kenya Red Cross, and the National Coordinator of the Great Lakes Region (the Committee's coordinator). ${ }^{4}$

\section{Outputs}

Currently, the Committee is moving toward formalization within the Kenyan government and has drawn up a draft national legal notice seeking to formally institutionalize its mandate within the state. Although still in an interim period of consolidation, the Committee is already active, in carrying out its stated mandate under the auspices of the ICGLR. To strengthen the effectiveness of its operations, the KNC has established subcommittees on: the construction of a National Memorial for Post-Election Violence, Early Warning, Rules, Resource Mobilization, a national Genocide Prevention Bill and Policy, as well as the use of punishment as a preventive mechanism. The KNC has also undertaken training and capacity building initiatives for its members aimed at enhancing their knowledge and skills surrounding the prevention of atrocity crimes.

Ahead of the general elections held on March 4, 2013, the KNC held a Peace Forum in the Coast region for County Commissioners, Provincial Commissioners, and community leaders. Using this precedent, the Committee has held peace fora in hotspots for potential violence around the country. The KNC also carried out an initiative of public messaging, distributing pamphlets with peace messaging in Nairobi and other at-risk regions. ${ }^{5}$ In order to respond to the atrocity crime risk factors presented by the outbreak of violence following the now-annulled August 2017 election, Committee members are working in the field to mediate disputes and diffuse tensions at the local level among other preventive efforts.

Previously, the KNC co-organized a capacity building seminar in July of 2015 with AIPR that focused on the memorialization of violence related to the 2007-2008 electoral process. The seminar hosted participants from several Kenyan government bodies for training, with the objective of examining the state of prevention in Kenya and the surrounding region, as well as developing capacity to plan and implement prevention projects at national and grassroots levels. Additionally, the KNC participated in the Sixth Regional Committee Meeting and Training of the Regional and National Committee Members on Prevention and Punishment of the Crime of Genocide, War Crimes, Crimes Against Humanity and All Forms of Discrimination in the Great Lakes, held in January of 2015 in Kampala, Uganda. The activity provided ICGLR and state representatives with a space to share best practices and learn about the latest trends in prevention. The KNC also participated in an ICGLR Regional Committee Meeting in Congo (Brazzaville) in December of 2015, which focused on the situation in Burundi.

Finally, in February of 2016, the Committee attended a meeting organized by AIPR in Kampala, Uganda, and also contributed to the GAAMAC II meeting held in Manila, Philippines.

\footnotetext{
${ }^{4}$ AIPR, Effective and Sustainable Prevention, 5.

${ }^{5}$ The Auschwitz Institute for Peace and Reconciliation (AIPR), National Mechanisms for the Prevention of Genocide and other Atrocity Crimes: Pursuing Institutionalization of the Prevention Agenda (New York: 2017), 6-7, accessed December 28, 2017, http://www.auschwitzinstitute.org/wp-content/uploads/2017/05/2017-National-Mechanisms-Booklet.pdf.
} 
In March of 2016, the Committee participated in a workshop held by the Budapest Centre for the International Prevention of Genocide and Mass Atrocities, as well as a training seminar conducted by the Tanzanian National Committee in collaboration with AIPR in Dar es Salaam. Additional training programs for committee members took place in December of 2016, February and August of 2017 in collaboration with AIPR. These programs focused on early warning and risk assessment frameworks and brought in partners from the region including the East African Community to develop and expand upon current models in place for the period leading up to the general elections in August 2017.

The Committee also has a number of planned activities, including:

- Establishing a memorial, or memorials, such as peace parks in the capital city of Nairobi and other strategic locations to commemorate past atrocities and promote prevention. The KNC is collaborating with the government of Argentina on this project, as Argentina has vast experience in establishing public memorials to commemorate atrocity crimes committed on their soil.

- Spearheading the formulation of genocide prevention policy and legislation.

- Further considering ways in which punishment can be used as a mechanism to prevent future atrocities in collaboration with the Kenyan Judiciary. ${ }^{6}$

\section{The Tanzania National Committee for the Prevention and Punishment of the Crime of Genocide, War Crimes, Crimes Against Humanity and All Forms of Discrimination History}

The Tanzanian National Committee (TNC) was established under the auspices of the ICGLR Protocol for the Prevention and Punishment of Genocide, War Crimes, Crimes Against Humanity and All Forms of Discrimination. Tanzania established their National Committee in February of 2012, making it the first ICGLR Member State to do so.

The government prioritized its establishment of the Committee given the country's history of religious tensions and internal land disputes - both recognized as potential flashpoints for future violence. Another potential spark for conflict stems from the presence, within Tanzanian borders, of refugees and groups of foreign citizens who oppose foreign governments. For decades, Tanzania has received refugees from neighboring countries such as Rwanda and has recently mediated peace talks in Burundi and Rwanda. Moreover, the country has hosted foreign opposition groups from many countries in southern Africa. According to the Chair of the National Committee, Felistas Mushi, these risk factors are a by-product of Tanzania's inclusive culture. As explained by Ms. Mushi, Tanzanians strive to help fellow citizens and their neighbors build peaceful and tolerant societies. The requirements maintained by the Protocol, she said, are therefore complementary to Tanzania's inherent commitments in this regard. ${ }^{7}$

Mandate

Tanzania's National Committee seeks to prevent the crime of genocide, war crimes, crimes against humanity, and all forms of discrimination through:

- Regularly monitoring situations and processes that could lead to these crimes;

- Collecting and analyzing relevant information;

- Alerting the government and proper authorities in a timely fashion to undertake

- immediate measures to prevent the commission of these types of crimes;

- Recommending measures to effectively prevent them;

- Fighting impunity for the crimes listed above;

\footnotetext{
${ }^{6}$ The Auschwitz Institute for Peace and Reconciliation (AIPR), National Mechanisms for the Prevention of Genocide and other Atrocity Crimes: Durable Solutions to Challenges in Effective Prevention (New York: 2016), 7, accessed December 28, 2017, http://www.auschwitzinstitute.org/wp-content/uploads/2016/01/2016-National-Mechanisms-Booklet-ElectronicVersion.pdf.

${ }^{7}$ AIPR, Effective and Sustainable Prevention, 7.
} 
- Raising awareness on the processes that enable these crimes and educating others about

- prevention to promote the implementation of peace and reconciliation programs;

- Recommending policies and measures to guarantee the rights of victims of these crimes to truth, justice, compensation, and rehabilitation; and

- Carrying out any further tasks the Minister of Justice may entrust to the Committee under its mandate.

\section{Structure}

The Tanzanian Committee is comprised of members of the government, human rights institutions, civil society, religious institutions, and academia. Government officials from the following institutions are represented: the Ministry of Constitutional and Legal Affairs, which holds the Chair, the President's Office, the Prime Minister's Office, the Ministry of Foreign Affairs and International Cooperation, the Ministry of Defense and National Service, the Ministry of Home Affairs, the Ministry of Community Development, Gender and Children, the Attorney General's Chambers, the Ministry of Education and Vocational Training, the Office of the Director of Public Prosecutions, the State Police Force, the Ministry of Information, Youth, Culture and Sports, the Ministry of East African Cooperation, and the Commission for Human Rights and Good Governance. From civil society, there is representation from the Centre for Foreign Relations, the Mwalimu Nyerere Foundation, and the Legal and Human Rights Center. Both Catholic and Muslim communities have representation on the Committee through the Inter-Religious Council. Finally, the University of Dar es Salaam and the Legal Aid Committee of the University of Dar es Salaam School of Law are also members.

The process of selecting members was based on the model provided in the ICGLR's Rules of Procedure of the Regional Committee and was also localized according to the Tanzanian administrative system. The main goal was to draw membership from all key ministries and sectors dealing with peace and security, either directly or indirectly. Throughout its work, the Committee invites a broad spectrum of institutions to assist in implementing its operational strategy. For example, capacity building seminars for members have been conducted in collaboration with AIPR and other international organizations. The Committee's operational strategy includes the development of partnerships and management capacity to enable further cooperative work. The Committee believes that broad participation and inclusiveness of Tanzania's citizenry in the formulation and implementation of preventive policy ensures operational effectiveness. ${ }^{8}$

\section{Outputs}

The Committee has conducted interfaith peace forums and programs involving both civil society and political leaders, and has developed tailored training and technical assistance programs to increase capacity in order to carry out its mandate. These training programs have been supported by international civil society organizations, as well as the UN OSAPG. The first of these trainings took place in March and October of 2014 and covered such topics as electoral violence, land conflict, inter-religious tensions, and natural resource-based conflict. More recently, in March of 2016, the TNC and AIPR co-organized an additional training to:

- Familiarize participants with the concept of genocide and other atrocity crimes, the relationship between them, and the processes by which they occur;

- Empower participants with the practical competencies (knowledge and skills) necessary to be able to identify, deter, and limit the impact of genocide and other atrocity crimes; and

- Strengthen the capacity of leaders, as shapers of political will, to become agents of atrocity crime prevention with a heightened degree of sensitivity and awareness to the role of governmental and non-governmental actors in zones of conflict.

\footnotetext{
${ }^{8}$ Ibid., 8.
} 
The main topics discussed during this training were the prevention and management of electoral violence, early warning and response tools for atrocity crimes prevention, and the construction of institutional synergies between regional and national mechanisms for prevention. This event served as the third in a series of capacity building training seminars and has been followed by additional programming already taking place in 2017.

The success of interfaith peace forums towards building peace and social cohesion in Tanzania is noteworthy. These forums have covered concrete strategies and opportunities to prevent genocide in Tanzania as well as the role of religious leaders in peacebuilding. More specifically, genocide prevention strategies most relevant to the Tanzanian context were identified as:

- Fostering peaceful cooperation, interactions, and coexistence between different religious faiths in peacetime;

- Encouraging the media to adhere to established professional ethics and act as positive forces relative to building national unity, social cohesion, and sustainable development;

- Building political and governance systems on the principles of transparency, accountability, and the timely administration of justice; and

- Eliminating nepotism, discrimination, and injustice in national institutions.

Finally, the TNC is currently in the process of establishing a National Centre for Conflict Early Warning and Early Response. The objective of the Centre will be to build an efficient framework for information sharing and communication, utilizing available technologies among governmental and nongovernmental actors. The resulting network will include local and national-level representatives and function with the goal of providing timely advice and policy recommendations for burgeoning conflicts and threats to peace and security in Tanzania. ${ }^{9}$

\section{The Uganda National Committee for the Prevention and Punishment of the Crime of Genocide, War Crimes, Crimes Against Humanity and All Forms of Discrimination History}

Like the Tanzanian and Kenyan National Committees, the Ugandan National Committee (UNC) was established under, and in compliance with, the ICGLR Protocol for the Prevention and Punishment of Genocide, War Crimes, Crimes Against Humanity and All Forms of Discrimination. The Ugandan National Committee was officially launched on October 15, 2012, in Entebbe, Uganda, with support from the UN OSAPG. A preliminary one-day training was held for members of the Committee to coincide with the launch, at which time a six-month work plan was developed. The plan addressed the unique challenges facing Uganda - a country where the process of genocide has unfolded in the past and where the risk of atrocity crimes remains.

\section{Mandate}

Uganda's National Committee seeks to prevent the crime of genocide, war crimes, crimes against humanity, and all forms of discrimination by:

- Regularly monitoring situations and processes that could lead to these crimes;

- Collecting and analyzing relevant information;

- Alerting the government and proper authorities in a timely fashion to undertake immediate measures to prevent the commission of the above crimes;

- Recommending measures to effectively prevent these types of crimes;

- Fighting against impunity for the above crimes;

- Raising awareness and providing education on the processes that enable these crimes to promote the implementation of peace and reconciliation programs;

- Recommending policies and measures to guarantee the rights of victims of these crimes to truth, justice, compensation, and rehabilitation; and

${ }_{9}^{9}$ AIPR, Pursuing Institutionalization, 8. 
- Carrying out any further tasks the Minister of Justice may entrust to the Committee under its mandate.

Structure

Unlike others in the region, the Ugandan National Committee features a member of civil society as its chairperson. While all national committees in the Great Lakes Region include a significant number of non-governmental experts and practitioners, this structure is unique to Uganda. The UNC is comprised of the Chair and Secretary, a Treasurer, who represents academia and the legal community, and a representative from the Human Rights Commission of Uganda as the Communications Director. Additional members include representatives from the Ministry of Foreign Affairs, the Ministry of Justice and Constitutional Affairs, the Ministry of Gender, the Uganda People's Defense Force, and other civil society organizations. ${ }^{10}$

\section{Outputs}

In August 2014, the UNC engaged in community-level consultative and mediation meetings to address tensions in Western Uganda. This led to the diffusion of violent escalations and has served as a model for further peace talks and mediation techniques undertaken by the Committee. In 2015, the Committee completed an initial assessment of national strengths and weaknesses from the perspective of atrocity prevention. The main policy gap that was discovered concerned domestic legislation for atrocity crimes. The Committee subsequently forged a partnership with a group of parliamentarians to draft a bill defining punishment for the crime of genocide as well as institutionalizing the UNC within the state apparatus. The "Genocide Bill", as it is most commonly called, was introduced on the floor of parliament and was referred to a select committee. The UNC is working to support the passage of the bill into law over the coming parliamentary sessions, which will give Uganda a domestic legal framework for the National Committee and its mandate.

Later, in December of 2015, the Committee led a training session, held in collaboration with AIPR, for various members of the National Committees in the ICGLR region. The primary objectives of the seminar were to provide background information on past experiences and to address new challenges and lessons learned on thematic issues involving the work of National Committees in the Great Lakes Region of Africa. It also worked to provide state leaders and National Mechanisms with policy and programmatic recommendations towards further institutionalization and increased sustainability of efforts for the prevention of genocide and other atrocity crimes. Members of the Ugandan Committee also participated in the March 2016 training in Tanzania, described in the previous section. During the workshop, Ugandan representatives proposed initiatives for the translation of existing human rights documents and legislation into local languages as well as classroom and extracurricular programs for youth on the prevention of paramilitary mobilization. Paramilitary mobilization remains an ongoing problem and one to which the Committee has devoted much of its work. Unfortunately, the successful and complete implementation of these programs is still pending the availability of resources. ${ }^{11}$

\section{The Commission for International Humanitarian Law of Costa Rica (La Comisión Costarricense de Derecho Internacional Humanitario - CCDIH) \\ History}

The Costa Rican government has looked to the existing body of the CCDIH to manage the state's agenda of atrocity crimes prevention. The Commission was created by an Executive Order in 2004 as an inter-ministerial/inter-departmental body with an advisory role to the Executive branch of the government. The CCDIH is also mandated to implement International Humanitarian Law (IHL) and propagate its dissemination. The Commission is led by the Ministry of Foreign Affairs and Culture, and is the only inter-ministerial mechanism in Costa Rica with a mandate and competency in issue areas pertaining to atrocity crimes prevention.

\footnotetext{
${ }^{10}$ AIPR, Effective and Sustainable Prevention, 10-11.

${ }^{11}$ AIPR, Durable Solutions, 9.
} 
Mandate

The mandate of the CCDIH concerning IHL is drawn from Costa Rica's commitments in this area, as party to various international treaties, regional agreements, and national regulatory legislation. As the CCDIH performs an advisory role on matters of compliance with relevant legal obligations and assists in the implementation and dissemination of regulations, it is, therefore, well suited to operationalize the agenda of atrocity crimes prevention, considering that the field of IHL holds many tools for prevention. Specifically, the CCDIH has a mandate to carry out the following functions:

- Make recommendations to the Executive on measures to be taken towards the implementation of international legal provisions in force relevant to International Humanitarian Law;

- Advise the Executive in the drafting of bills and regulations to ensure Costa Rica meets its international obligations in the field of International Humanitarian Law;

- Promote, encourage and support the dissemination of International Humanitarian Law in the institutions of the state and society in general, as well as taking appropriate action to this end;

- Attend meetings, seminars, and conferences related to International Humanitarian Law, with the nomination of the Executive;

- Promote and collaborate with the academic authorities of the country for the incorporation of International Humanitarian Law in educational curricula; and

- Suggest actions to contribute to the implementation and enforcement of international humanitarian law.

\section{Structure}

The Commission consists of three subcommittees, which manage various aspects of the body's work. They are a) Rules/Standards, b) Outreach and Education, and c) Protection of Cultural Property. The Commission includes the Ministry of Foreign Affairs, the Ministry of Education, the Ministry of Justice and Peace, the Ministry of Public Security, the Ministry of the Presidency, the Ministry of Health, the Ministry of Culture and Youth, the Attorney General's Office, the Judiciary, the Legislature, the Office of the Ombudsman, the University of Costa Rica, the National University, the National Council of Rectors, the Costa Rica Red Cross, and the Bar Association of Costa Rica. Thus, the CCDIH's membership exemplifies a whole of government approach in addition to including membership from other sectors, such as academia and civil society, which are extremely important to the development and implementation of effective preventive policy within the country. Furthermore, the efforts of Costa Rica in this area demonstrate that a government does not need to establish a new body to act as a National Mechanism, but instead can pursue this agenda through an existing mechanism that includes the necessary characteristics and competencies.

\section{Outputs}

The CCDIH has produced a number of outputs that contribute to the prevention of atrocity crimes in Costa Rica. Firstly, under the impetus of the Subcommittee on Rules and Standards, the Costa Rican Legislature has begun the process of incorporating protections for individuals and property under International Humanitarian Law (IHL) into the National Penal Code. Specifically, the drafted bill pertains to "Offenses Against Human Rights" and "Crimes Against Persons or Property Protected by International Humanitarian Law." The bill is awaiting discussion and debate during an upcoming plenary session of the Deputies of the Legislative Assembly.

Additionally, the Commission is currently working to address the status of the implementation of current international law into the National Penal Code as it pertains to the prevention of genocide. At this time, the crime of genocide is stipulated in Article 375 of the National Penal Code, however, according to the Commission, the stated law fails to fully meet the current international standards on atrocity crimes, particularly with regards to the Rome Statute of the International Criminal Court, of which Costa Rica is a signatory. Therefore, the Commission is 
recommending that Article 375 be amended to include specific and systematic acts of torture and forced disappearance, whether committed within the context of an armed conflict or outside of one.

Regarding its mandate to disseminate IHL, there are a number of activities the Commission has highlighted within the framework of its tenth anniversary, specifically pertaining to its work with state institutions and civil society. The CCDIH has been involved in the development of training programs for various actors from these sectors, including those from state security forces and legislative bodies. Additionally, the CCDIH organized a series of workshops to prepare for the XXXII International Conference of the Red Cross and Red Crescent, which was held from December 8-10, 2015 in Geneva, Switzerland. The first workshop, held on March 4, 2015, consisted of an introduction to IHL at the headquarters of the Bar Association of Costa Rica, with participation from civil society and legal professionals. Drawing on its mandate for collaboration with academic authorities, the CCDIH has recently established partnerships with the National University of Costa Rica and its Faculty of Law, which led to the initiation of a series of activities with the Commission, beginning in 2017.

Beyond these outputs, the Commission has been very active in communicating with the general public on issues concerning IHL and, by extension, the prevention of atrocity crimes. It has participated in various radio programs, such as Radio Universidad de Costa Rica, to speak about these topics and their importance in the lives of civilians. The CCDIH also sponsored the Race of the Red Cross in Costa Rica, which welcomed the participation of over 3,000 runners and carried messages related to IHL and the prevention of atrocity crimes.

The CCDIH also played an important role in the organization of the 2014 Global Action Against Mass Atrocity Crimes meeting held in San Jose. The Ministry of Foreign Affairs developed the program, in coordination with the governments of Denmark, Argentina, Switzerland and Tanzania. The event looked to bring together representatives from government and civil society around the world who serve as focal points for atrocity crimes prevention.

Finally, members of the CCDIH have participated in multiple training seminars held by AIPR in conjunction with Costa Rica's membership -through its Ministry of Foreign Affairs- in the Latin American Network for Genocide and Mass Atrocity Prevention. As a result, these participants are now able to organize training modules on topics related to genocide prevention for the members of the CCDIH. The last session, which took place on August 5, 2016, was called "Social Identity and the Creation of 'the Other'" (Identidad Social y la Creación del Otro), and was inspired by AIPR's curriculum for the Latin American edition of the Raphael Lemkin Seminar for Genocide Prevention. ${ }^{12}$

\section{Other Emerging Mechanisms}

Argentina

The government of Argentina is currently in the process of developing its National Mechanism for the Prevention of Genocide. The motivation for the creation of this inter-ministerial Mechanism comes from its national human rights policy, which has been in development since 2003. The establishment of a National Mechanism is complementary to a number of existing initiatives on fundamental human rights related to memory, truth, and justice that were launched in light of the country's civil-military dictatorship of 1976-1983.

In this sense, the National Mechanism is an essential institutional tool in the pursuit of higher levels of effectiveness in the prevention of genocide and other mass atrocities and is consistent with Argentina's active membership in the Latin American Network for Genocide and Mass Atrocity Prevention. The impetus for establishing a National Mechanism is also derived from Argentina's responsibility as a party to the United Nations Convention on the Prevention and Punishment of the Crime of Genocide. In this context, the Mechanism will serve as a tool for the domestication and operationalization of international law. Official authorization of the Mechanism will be provided through a Presidential Decree, which, as of the date of publication, is awaiting signature by the

${ }^{12}$ AIPR, Durable Solutions, 17-18. 
President.

The Argentinian National Mechanism has been designed as an inter-ministerial body with a well-defined framework for governmental and non-governmental actors playing a joint role in matters related to the prevention of atrocity crimes. In accordance with the Presidential Decree, the responsibilities of the Mechanism will include:

- Risk detection and early warning, including the development of procedures for the circulation and exchange of information within the government and to interested external parties, including civil society organizations and academic institutions, on various cases and situations posing a possible risk of atrocity. This also provides for the development of a standardized evaluation process for the data gathered.

- Systemic prevention and awareness, including the implementation of seminars and trainings on topics related to human rights, international humanitarian law, transitional justice, and other related topics under the prevention umbrella. This also provides for the implementation of standardized training curricula on anti-discrimination and atrocity prevention for public academic institutions, as well as institutions training civil servants. Lastly, it entails the development of an evaluation process for content in the media and mass communications.

- Collaboration and information exchange, including the establishment of procedural mechanisms for data processing and communications with the United Nations, as well as regional organizations, such as the Latin American Network for Genocide and Mass Atrocity Prevention.

The agencies that will participate in the National Mechanism and form its Coordinating Committee are the Ministries of Defense, Foreign Affairs and Worship, Justice and Human Rights, Education, Public Communications, and Institutional Reform and Democracy Building, as well as the Director of the Ministerial Cabinet, and the National Institute for the Prevention of Discrimination, Xenophobia and Racism. The Mechanism will also include a Committee for Genocide Prevention, which serves as a space for exchange with civil society organizations that are accredited by the Committee. Additionally, a Federal Network for Genocide Prevention will be established under the auspices of the National Mechanism, and will assist in developing the capacity of the Federal Government to coordinate prevention policy with provincial authorities.

As of the date of this publication, the nascent National Mechanism has only had preparatory meetings. However, the development of internal procedures is currently underway. The next step in the process will be the coordination of a National Action Plan for genocide prevention, which will be approved and put into place once the Presidential Decree has been signed and an assessment of the strengths and weaknesses of the current prevention policy framework has been conducted. ${ }^{13}$

Paraguay

The Truth, Justice and Reparation Directorate General of the Office of the Ombudsman, as well as the Ministry of Foreign Affairs of Paraguay - both Focal Points of the Latin American Network for Genocide and Mass Atrocity Prevention - have developed a bill to create a National Commission on the Prevention of Genocide and Mass Atrocities. The National Commission will facilitate interagency coordination among the various state agencies that have authority with respect to the prevention of genocide and other mass atrocities. The establishment of the Commission is supported by Paraguay's responsibilities derived from international law under the framework of the United Nations Convention on the Prevention and Punishment of the Crime of Genocide. To this end, the Ministry of Foreign Affairs acts as the focal point for the domestication of the Convention.

The Ministry of Foreign Affairs and the General Directorate for Truth, Justice and Reparations within the Office of the Ombudsman will chair the National Commission. The Commission shall

${ }^{13}$ AIPR, Effective and Sustainable Prevention, 17-18. 
consist of a primary and alternate representative from the following institutions: the Ministry of Foreign Affairs, the Office of the Ombudsman, the Ministry of Interior, the Ministry of Justice, the Ministry of Education and Culture, the Ministry of National Defense, the Judiciary, the Public Prosecutor, the Departments of the Armed Forces, the Ministry of Defense, Congress, and the State Police. The Commission reserves the right to call upon other institutions to join, should their membership become necessary.

The Congressional approval process for the bill creating the National Mechanism is currently underway, having been submitted for official consideration by six Senators. The prospective Commission is engaging with AIPR to develop capacity building programs, which will provide training to the body's members in order to assist in effectively carrying out its mandate. ${ }^{14}$

\section{Common Challenges and Innovative Solutions}

A number of the National Mechanisms featured in this article have existed in various forms for several years, and so it is appropriate to discuss some of the challenges that they are facing in effectively carrying out their mandates and highlight some of the innovative solutions they have developed to meet these obstacles head-on. Despite the varying geographical landscapes and even more diverse political and social narratives, a number of the challenges faced by National Mechanisms exhibit common themes.

States establishing new bodies often face difficulties in formally integrating the nascent Mechanism into the national government, such that it becomes an official body with resources allocated towards its mandate. This has been the experience of the Kenyan, Ugandan and Tanzanian National Committees, as well as the emerging Mechanisms in both Argentina and Paraguay. Each of these bodies is still waiting for proper legal integration through the necessary bureaucratic processes of their legislatures. Without this formalization, it remains very difficult for members to receive official leave from their primary professional duties to carry out programming and activities convened by the Mechanisms. Additionally, without proper funding allocated by their respective national legislature, the Mechanisms are obliged to seek resources from outside organizations in order to carry out their activities, which is not a sustainable practice.

While this lack of resources has continually proven to be among the most challenging obstacles to overcome, the Tanzanian, Ugandan, and Kenyan National Committees have been successful in employing outside funding to carry out a diverse array of programming. This includes the successful execution of a variety of training seminars, memorialization projects, and early warning activities, all while concurrently working towards formal institutionalization. As Felistas Mushi, Chairwoman of the Tanzanian National Committee, explains:

Our biggest strength as a Committee is our individual and collective commitment to prevention work. Despite all the challenges, the Committee has been able to accomplish what we have thus far because of this commitment, which has given us a great deal of credibility. ${ }^{15}$

\section{Conclusions and Lessons Learned}

In reviewing the outputs and activities of existing National Mechanisms for the Prevention of Genocide and other Atrocity Crimes, a small collection of lessons learned should be highlighted. Perhaps the most important of these lessons is that a National Mechanism does not necessarily need to be formally integrated into the central government to begin carrying out its stated mandate. We have seen this in the experiences of the Kenyan, Ugandan, and Tanzanian National Committees, as well as the nascent National Mechanisms in Argentina and Paraguay. In the same vein, a Mechanism also does not necessarily require its own resources to hold effective programming such as trainings, peace forums, and other meetings at the outset. Collaboration with outside partners, whether through regional bodies or international civil society organizations, foundations, or donor governments, has proven to be an effective method for gathering the requisite resources and

\footnotetext{
${ }^{14}$ AIPR, Pursuing Institutionalization, 11.

${ }^{15}$ AIPR, Effective and Sustainable Prevention, 9.
} 
expertise to hold programming under their stated mandates in the initial stages of their work plan.

Additionally, the role that National Mechanisms play in the gathering and assessment of information has not been significantly constrained by a lack of formal institutionalization. As long as the members representing the various apparatuses of the national government and other sectors of society are present and committed to the mandate, in many cases information has continued to flow. This information has been utilized to issue formal policy recommendations to the proper authorities, often providing crucial early warning for potential crises.

That being said, it is also clear from discussions held between AIPR and members of the National Mechanisms that the long-term sustainability of these bodies, as well as their general effectiveness over the coming years through administration changes and shifting political contexts, depends heavily on their formal institutionalization into governmental structures and the allocation of budgetary resources that follows. Therefore, its long-term importance cannot be understated. This is why each of the Mechanisms has prioritized the active pursuit of institutionalization alongside their ongoing activities.

Based on the collective experiences of existing bodies, the following considerations are important in the establishment of new National Mechanisms:

Mandate: The establishment of a National Mechanism often requires that a national government take a strong policy position on atrocity prevention as a national priority. This will not only aid in the inception of a new Mechanism, but also allow for the future actions of the body to be framed as part of this national-level policy. In the case of the African Great Lakes Region, the 2006 Protocol that mandated the establishment of a regional committee and individual national committees continues to constitute the main point of departure.

Membership: What areas of government should be represented, and why? Comprehensive membership confers many benefits and extends beyond government. Civil society organizations are also seen to be key partners in an effective prevention agenda, occupying both formal advisory roles and participating directly alongside governmental members of a National Mechanism.

Structure: It is important include both horizontal and a vertical considerations. Horizontally, all relevant departments must be included. Vertically, Mechanisms can often produce policies that would require implementation by agents within the nationallevel administration, as well as those from regional and local power structures. While this may be clearer in federated states, it is not exclusive to them.

Goal: It is important to emphasize that the objective of these mechanisms is the design of unified national policies for the prevention of genocide and other atrocity crimes. Inherent in this is an emphasis on "upstream" prevention, meaning that National Mechanisms aim to address the steps leading up to violence, taking measures to halt these processes before we see any resulting casualties.

Function: National Mechanisms are established to carry out two main functions. The first of which is to carry out a system-wide assessment of strengths and weaknesses from the perspective of atrocity prevention. Ideally, the results of the assessment should lead the discussion on further functions of the mechanism. Secondly, they are established to support the design, implementation, and coordination of national policies for prevention.

Outputs: In order to maintain institutional momentum and demonstrate efficacy, there is a need to realize concrete achievements. These most often include trainings, published 
national strategies, inter-ministerial forums, and a variety of other programs or policy recommendations. The National Mechanism needs to display value added to ensure its sustainability.

Impact: Ideally, the process of establishment should build in a system of impact evaluation. The National Mechanism should also be flexible in amending its work plan in order to take the results of any evaluation into account.

Budget: National Mechanisms can rely on international assistance in the short term, but they must quickly become self-sustaining, which requires inclusion in the national budget. This step constitutes a true indication of the priority that a national government gives to the establishment of a National Mechanism. ${ }^{16}$

These lessons are important to note for countries working to establish their own National Mechanisms within the particular context of their governmental structure and the societal conditions concerning atrocity crimes prevention. Genocide and other atrocity crimes are complex social problems that must be addressed effectively by the societal collective as a whole. Thus, it follows that the state must employ a whole of government approach to the prevention of such crimes, bringing in those representatives who have responsibilities concerning prevention to the planning table, as well as non-state actors who play a key role in prevention policy implementation.

In Confronting Evil: Engaging Our Responsibility to Prevent Genocide, James Waller notes the importance of National Mechanisms in the upstream prevention of atrocity crimes. To mitigate risk factors for atrocity associated with governance, conflict history, economic conditions, and social cohesion, he finds that "initiatives that are highly responsive to the unique internal dynamics of the society are crucial in building a state's resilience, reducing its susceptibility to genocide and, ultimately, reinforcing a state's sovereignty." ${ }^{\prime 17} \mathrm{He}$ follows this by citing the work of a number of National Mechanisms featured in this article as examples of effective frameworks for civilian protection. Bridget Moix has asserted that:

...Turning genocide prevention inside-out to focus first on supporting and strengthening local capacities for peace within a society, linking them more effectively with regional and global backup response systems, would not only save lives, it would also be significantly less expensive and less damaging, and holds greater promise for finally closing the prevention gap so often debated. ${ }^{18}$

The work of National Mechanisms represents a more community-based or localized approach to atrocity prevention, inclusive of both state and non-state actors within society. Moix points to various examples of what she calls "local peace agency," ${ }^{19}$ which provides important opportunities to the field of genocide prevention, challenging the dominant assumptions about external interventions. She goes on to explain that such localized approaches my help "re-orient our theory and practice in ways that can help [us] move upstream to earlier prevention, break repeating cycles of violence, and ensure more sustainable recovery and reconciliation processes over the long-term." ${ }^{20}$

This growing understanding within the field, one that supports local solutions to local problems and involves both state and non-state stakeholders in the development of prevention strategies, is reflected in the emergence of National Mechanisms and has manifested in their programming and

\footnotetext{
${ }^{16}$ AIPR, Durable Solutions, 24-25.

${ }^{17}$ James Waller, Confronting Evil: Engaging Our Responsibility to Prevent Genocide (New York: Oxford University Press, 2016), 196-197 and 163.

${ }^{18}$ Bridget Moix, "Turning Atrocity Prevention Inside-Out: Community-Based Approaches to Preventing, Protecting, and Recovering from Mass Violence," Genocide Studies and Prevention: An International Journal 9, no. 3 (2016), 62.

${ }^{19}$ Ibid., 60 .

${ }^{20}$ Ibid.
} 
activities. The proliferation of these bodies in states around the world lends itself to the notion that National Mechanisms represent an inclusive approach to atrocity prevention that has had a positive impact on our field and will continue to do so.

\section{Bibliography}

Moix, Bridget. "Turning Atrocity Prevention Inside-Out: Community-Based Approaches to Preventing, Protecting, and Recovering from Mass Violence." Genocide Studies and Prevention: An International Journal 9, no. 3 (2016): 59-69. https://doi.org/10.5038/19119933.9.3.1313

Scheffer, David. "Genocide and Atrocity Crimes," Genocide Studies and Prevention: An International Journal 1, no. 3 (2006): 229-250. https://doi.org/10.3138/E832-0314-6712-60H3

The Auschwitz Institute for Peace and Reconciliation (AIPR). National Mechanisms for the Prevention of Genocide and other Atrocity Crimes: Effective and Sustainable Prevention Begins at Home. New York, 2015. Accessed December 28, 2017. http://www.auschwitzinstitute.org/wp-content/ uploads/2015/06/AIPR National Mech Booklet 2015.pdf.

---------. National Mechanisms for the Prevention of Genocide and other Atrocity Crimes: Durable Solutions to Challenges in Effective Prevention. New York, 2016. Accessed December 28, 2017. http://www.auschwitzinstitute.org/wp-content/uploads/2016/01/2016-NationalMechanisms-Booklet-Electronic-Version.pdf.

--------. National Mechanisms for the Prevention of Genocide and other Atrocity Crimes: Pursuing Institutionalization of the Prevention Agenda. New York, 2017. Accessed December 28, 2017. http://www.auschwitzinstitute.org/wp-content/uploads/2017/05/2017-NationalMechanisms-Booklet.pdf.

Waller, James. Confronting Evil: Engaging Our Responsibility to Prevent Genocide. New York: Oxford University Press, 2016. 